\title{
High-rise Building Group Regional Fire Risk Assessment Model Based on AHP
}

\author{
Wei Zhu, Qiuju You \\ Beijing Research Center of Urban Systems Engineering, Beijing 100035, P.R. China \\ Beijing Key Laboratory of Operation Safety of Gas, Heating and Underground Pipelines, Beijing 100035, P.R. China \\ E-mail: zhuweianquan@126.com,yqjbyq@163.com
}

Received 26 September 2015

Accepted 20 January 2016

\begin{abstract}
Based on Analytic Hierarchy Process (AHP), a regional fire risk assessment model is developed for high-rise building group considering the fire danger degree, basic characters of the high-rise building group and fire control capability. The impact factors, values of typical risk parameter and the weight of each index are analyzed. An assessment program is further developed using Matlab, to perform the risk assessment procedures. The model is then applied to the regional fire risk evaluation of a high-rise building group.
\end{abstract}

Keywords: High rise building, Fire, Risk assessment, AHP

\section{Introduction}

With the development of city construction and the increase of population density, land is becoming a limited resource. In order to overcome the problem, more and more high-rise buildings are built. High-rise building fires have many special characteristics, such as the diversity of blazing, factors, various ways of fires spreading, the difficulty of evacuation and saving activities. Due to the importance of fire safety for the high-rise building, many studies have been conducted to analyze the fire risk of the high-rise building. Chen et al.(Chen et al. 2012) has analyzed the fire accident using the accident tree analysis method and the principal theory of safety system engineering. Liu et al.(Liu et al. 2012) has analyzed the factors that can cause high-rise building fires, and a partial event tree has been built. Sun et al.(Sun \& Luo, 2014) has madea case study for a super high-rise building to expatiate the procedure and methodology of fire risk assessment for super high-rise buildings. Cowlard et al.(Cowlardet al.2013) has made some studies on the fire safety design for tall buildings.

For a high-rise building group in a community, the fire safety is more important. Because of the complex of itself, such as more high-rise buildings, limited spacing between buildings, once a fire happened, fire spreading may arise. As a typical disaster in urban public safety, high-rise building group fire should attract more attention and be treated seriously. However, very limited work has been reported for fire risk assessment of high-rise building group. Here, based on the characteristic of high-rise building group, Analytic Hierarchy Process (AHP) is used to develop a regional fire risk assessment model for high-rise building group. As a risk assessment method, AHP has been used by many researchers in evaluation of fire risk, see (Wang et al.2012; Ren,2012; Zhang, 2013; Gao, 2014; and Omidvariet al. 2015) for more details. Then the model is applied to the fire risk evaluation of a high-rise building group.

\section{Analytic Hierarchy Process}

The first step of AHP is to establish AHP structure index system. The AHP structure index system can be divided into several layers according to the influence factors, and the first layer only has one factor. After that the structure judgment matrix should be built. For the factors which are below a same upper factor are compared with each other to confirm the weights of each factors for the same upper factor based on Table 1, and then the structure judgment matrix is obtained as Eq. (1).

$$
A=\left[\begin{array}{cccc}
a_{11} & a_{12} & \cdots & a_{1 n} \\
a_{21} & a_{22} & \cdots & a_{2 n} \\
\cdots & \ldots & \ldots & \ldots \\
a_{n 1} & a_{n 2} & a_{n 3} & a_{n n}
\end{array}\right]
$$


Table 1. Importance degree.

\begin{tabular}{|c|c|c|}
\hline$i, j$ compare & $a_{i j}$ & signification \\
\hline$i$ is as important as $j$ & 1 & $i$ is as important as $j$ \\
\hline$i$ is a little more important than $j$ & 3 & The former factor is a little more important than the latter \\
\hline$i$ is obviously more important than $j$ & 5 & $\begin{array}{l}\text { The former factor is obviously more important than the } \\
\text { latter }\end{array}$ \\
\hline$i$ is much more important than $j$ & 7 & The former factor is much more important than the latter \\
\hline$i$ is extremely more important than $j$ & 9 & $\begin{array}{l}\text { The former factor is extremely more important than the } \\
\text { latter }\end{array}$ \\
\hline- & $2,4,6,8$ & $\begin{array}{l}\text { The middle value between the above neighboring } \\
\text { judgments }\end{array}$ \\
\hline
\end{tabular}

where $a_{i j}$ is the result, $n$ is the number of factors. Obviously, $a_{i j}>0, a_{i i}=1$, and $a_{i j}=1 / a_{j i}$. In order to obtain the weight of each index, the eigenvector and the latent root of matrix should be counted, and the sum and product method is used as shown below.

$$
A w=\lambda_{\max } w
$$

where $w$ is the eigenvector, $\lambda_{\max }$ is the latent root of matrix, and they can be calculated as

$$
\begin{gathered}
w_{i}=\frac{\sum_{j=1} a_{i j}}{\sum_{k=1}^{n} \sum_{j=1}^{n} a_{k j}} i=1,2, \cdots, n \\
\lambda_{\max }=\sum_{i=1}^{n} \frac{(A w)_{i}}{n w_{i}}
\end{gathered}
$$

Then the consistency of the matrix should be tested with the index $C R$,

$$
\begin{gathered}
C R=\frac{C I}{R I} \\
C I=\frac{\lambda_{\text {max }}-n}{n-1}
\end{gathered}
$$

and the value of $R I$ is shown in Table 2 for different matrix order.

Table 2. $R I$ for different matrix order

\begin{tabular}{cccccccc}
\hline order & 1 & 2 & 3 & 4 & 5 & 6 & 7 \\
\hline$R I$ & 0 & 0 & 0.58 & 0.90 & 1.12 & 1.24 & 1.32 \\
\hline
\end{tabular}

If $C R<0.10$, the consistency of judgment matrix is good and the eigenvector is the weight of each index, or, the judgment matrix should be rebuilt.

\section{A fire risk assessment model for high-rise building group region}

\subsection{Comprehensive assessment factors}

Based on the causes of high-rise building group, the comprehensive factors are shown in Fig 1. The hierarchical model is divided into four layers. The first layer is the target layer, and the only factor was fire risk of high-rise building group. The second and third layer were criterion layers, the second layer include five factors. Every factor contains its subset of indicators. The last layer is index layer, and the model includes twenty five indexes.

\subsection{Weight of each factors}

According to the hierarchical model (Fig. 1), the judgment matrix can be built. Based on Table 1, the results of the pair-wise comparison of the target layer are expressed as Eq.7. And using Eqs. 2-4, the weight of each factors in second layer $U_{a}, U_{b}, U_{c}, U_{d}, U_{e}$ is

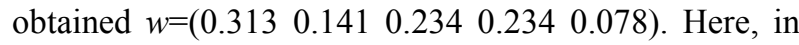
order to make the operation convenient, a procedure is developed using Matlab as shown in Fig. 2.

$$
A=\left[\begin{array}{ccccc}
1 & 2 & 2 & 2 & 3 \\
1 / 2 & 1 & 1 / 2 & 1 / 2 & 2 \\
1 / 2 & 2 & 1 & 1 & 3 \\
1 / 2 & 2 & 1 & 1 & 3 \\
1 / 3 & 1 / 2 & 1 / 3 & 1 / 3 & 1
\end{array}\right]
$$




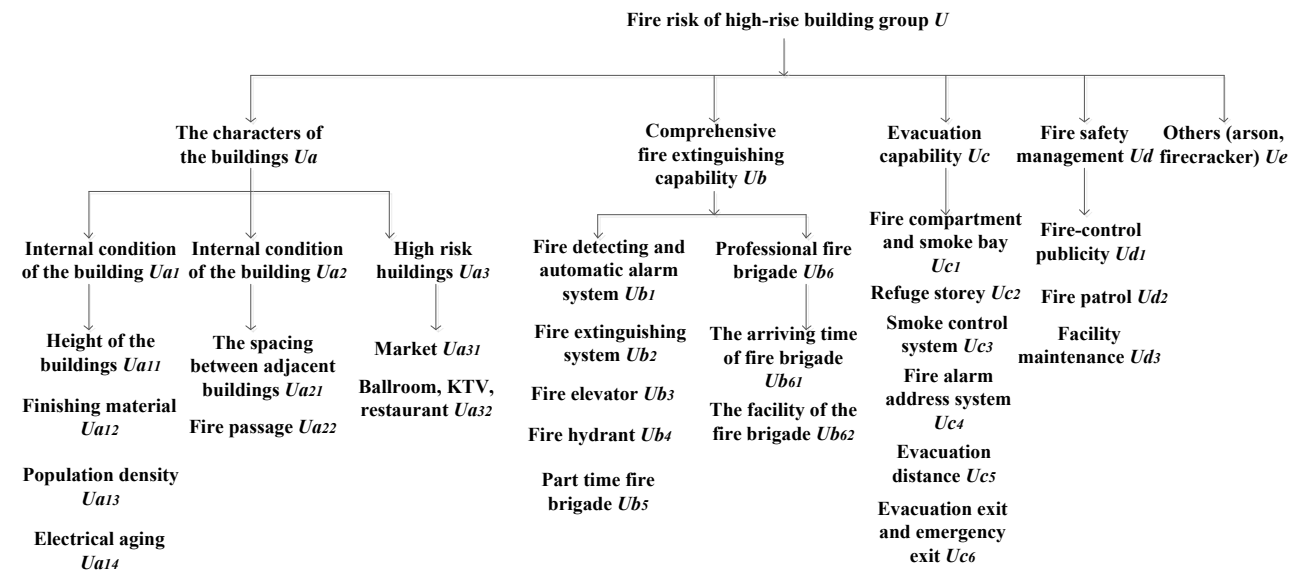

Fig. 1. Fire risk assessment hierarchical model of the high-rise building group.

Result of subset $U_{a}, U_{b}, U_{c}, U_{d}$, are shown respectively as Eqs. 8-11. And the weight of the factors in layer three is

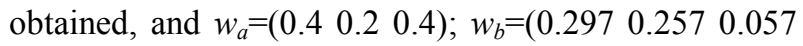
$0.1780 .1120 .099) ; w_{c}=\left(\begin{array}{llll}0.065 & 0.218 & 0.2620 .105 & 0.175\end{array}\right.$ $0.175) ; w_{d}=\left(\begin{array}{lll}0.072 & 0.339 & 0.589\end{array}\right)$.

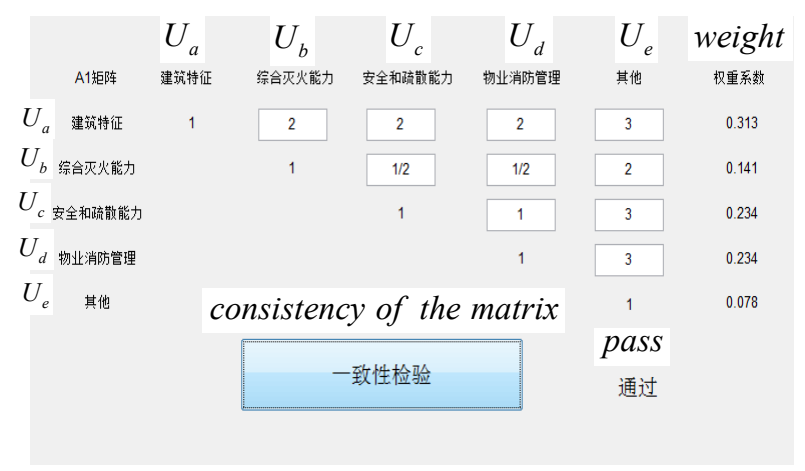

Fig. 2. Judgment matrix and consistency.

$$
\begin{gathered}
A_{a}=\left[\begin{array}{ccc}
1 & 2 & 1 \\
1 / 2 & 1 & 1 / 2 \\
1 & 2 & 1
\end{array}\right] \\
A_{b}=\left[\begin{array}{cccccc}
1 & 1 & 5 & 2 & 3 & 3 \\
1 & 1 & 3 & 2 & 3 & 3 \\
1 / 5 & 1 / 3 & 1 & 1 / 3 & 1 / 2 & 1 / 2 \\
1 / 2 & 1 / 2 & 3 & 1 & 1 & 3 \\
1 / 3 & 1 / 3 & 2 & 1 & 1 & 1 \\
1 / 3 & 1 / 3 & 2 & 1 / 3 & 1 & 1
\end{array}\right]
\end{gathered}
$$

$$
\begin{gathered}
A_{c}=\left[\begin{array}{cccccc}
1 & 1 / 2 & 1 / 3 & 1 / 2 & 1 / 3 & 1 / 3 \\
2 & 1 & 1 & 2 & 2 & 2 \\
3 & 1 & 1 & 3 & 2 & 2 \\
2 & 1 / 2 & 1 / 3 & 1 & 1 / 2 & 1 / 2 \\
3 & 1 / 2 & 1 / 2 & 2 & 1 & 1 \\
3 & 1 / 2 & 1 / 2 & 2 & 1 & 1
\end{array}\right] \\
A_{d}=\left[\begin{array}{cccc}
1 & 1 / 5 & 1 / 7 \\
5 & 1 & 1 / 3 \\
7 & 3 & 1
\end{array}\right]
\end{gathered}
$$

Result of subset $U_{a 1}, U_{a 2}, U_{a 3}, U_{b 6}$, are shown respectively as Eqs. 12-15. And the weight of the factors in layer four is obtained, and $w_{a l}=(0.225$ $0.0670 .5390 .169) ; w_{a 2}=(0.8330 .167) ; w_{a 3}=\left(\begin{array}{ll}0.5 & 0.5\end{array}\right)$; $w_{b 6}=(0.3330 .667)$.

$$
\begin{gathered}
A_{a l}=\left[\begin{array}{cccc}
1 & 3 & 1 / 4 & 2 \\
1 / 3 & 1 & 1 / 5 & 1 / 3 \\
4 & 5 & 1 & 5 \\
1 / 2 & 3 & 1 / 5 & 1
\end{array}\right] \\
A_{a 2}=\left[\begin{array}{cc}
1 & 5 \\
1 / 5 & 1
\end{array}\right] \\
A_{a 3}=\left[\begin{array}{ll}
1 & 1 \\
1 & 1
\end{array}\right] \\
A_{b 6}=\left[\begin{array}{ll}
1 & 1 / 2 \\
2 & 1
\end{array}\right]
\end{gathered}
$$

According to the hierarchical model and the weight of every layer, the weight of every factor can be achieved. 
The weight is shown in the following $\mathrm{W}=(0.028,0.008,0.067,0.021,0.052,0.010,0.062$, $0.062,0.041,0.036,0.008,0.025,0.026,0.004,0.009$, $0.015,0.051,0.061,0.024,0.040,0.040,0.016,0.079$, $0.137,0.078)$.

\subsection{Comprehensive assessment model}

We could not quantify fire risk of the high-rise building group only based on the weight of the factors. In this study, the score of each factor of a certain high-rise building group should be determined with the aid of the expert scoring. And Table 3 shows the scoring criteria.

During the assessment, each factor has a score on the basis of Table 3 . And then it will be multiplied by its weight. The comprehensive score $R$ of the high-rise building group will be obtained by the summation of all the factors.

The relationship between the fire risk grades and the scale is shown detailed as follow

$2 \leq R<4$ low-grade risk, $4 \leq R<6$ moderate risk, $6 \leq R<8$ high risk, $8 \leq R \leq 10$ super highrisk

\section{Application for case study}

Then a high-rise building group has been selected for example. The area of the whole high-rise building group is 12.28 hectares, and the total construction area is 700000 square meters with ground floor total area of
190000 square meters. It contains 18 apartments, 2 office buildings, 4 small offices and a large number of annexes. Supporting facilities include kindergarten and club. The height of the highest building is $100 \mathrm{~m}$. The scores of each factors is shown in Table 4.

Here, the Matlab procedure is also used to make the assessment based on the Comprehensive assessment model built in this study, and part of the assessment process is shown in Fig. 3.

According to the score and weight of every factor the assessment of the fire risk of the high-rise building group can be done as shown in Fig. 3. The quantitative result of the building group is 4.85681 . The fire risk grade is moderate risk.

\section{Concluding Remarks}

Based on the Analytic Hierarchy Process (AHP), a regional fire risk assessment model is developed for high-rise building group. Fire risk assessment hierarchical model is built which contains twenty five impact factors, and the weights of each index are obtained using AHP method. Marking criterion of each factor is provided. An assessment program is further developed using Matlab, to perform the risk analysis and evaluation procedures. The model is then applied to the regional fire risk evaluation of a high-rise building group.

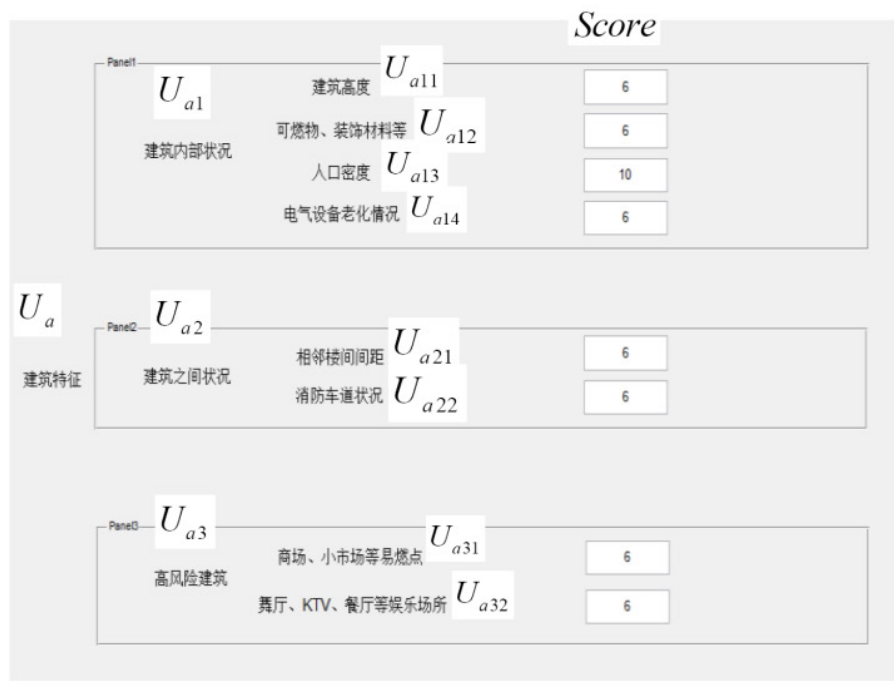

(a)

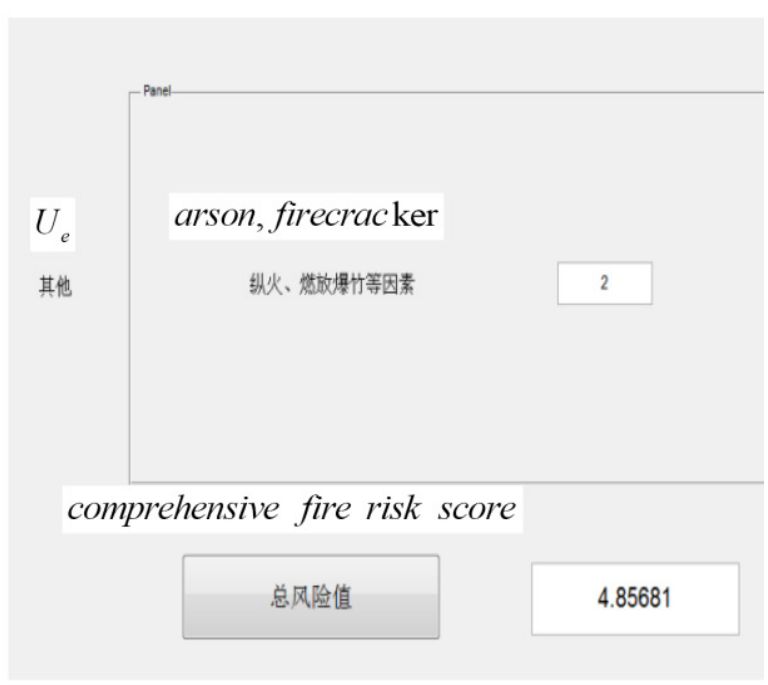

(b)

Fig. 3. Comprehensive assessment process. 
Table 3. Marking criterion of each factor.

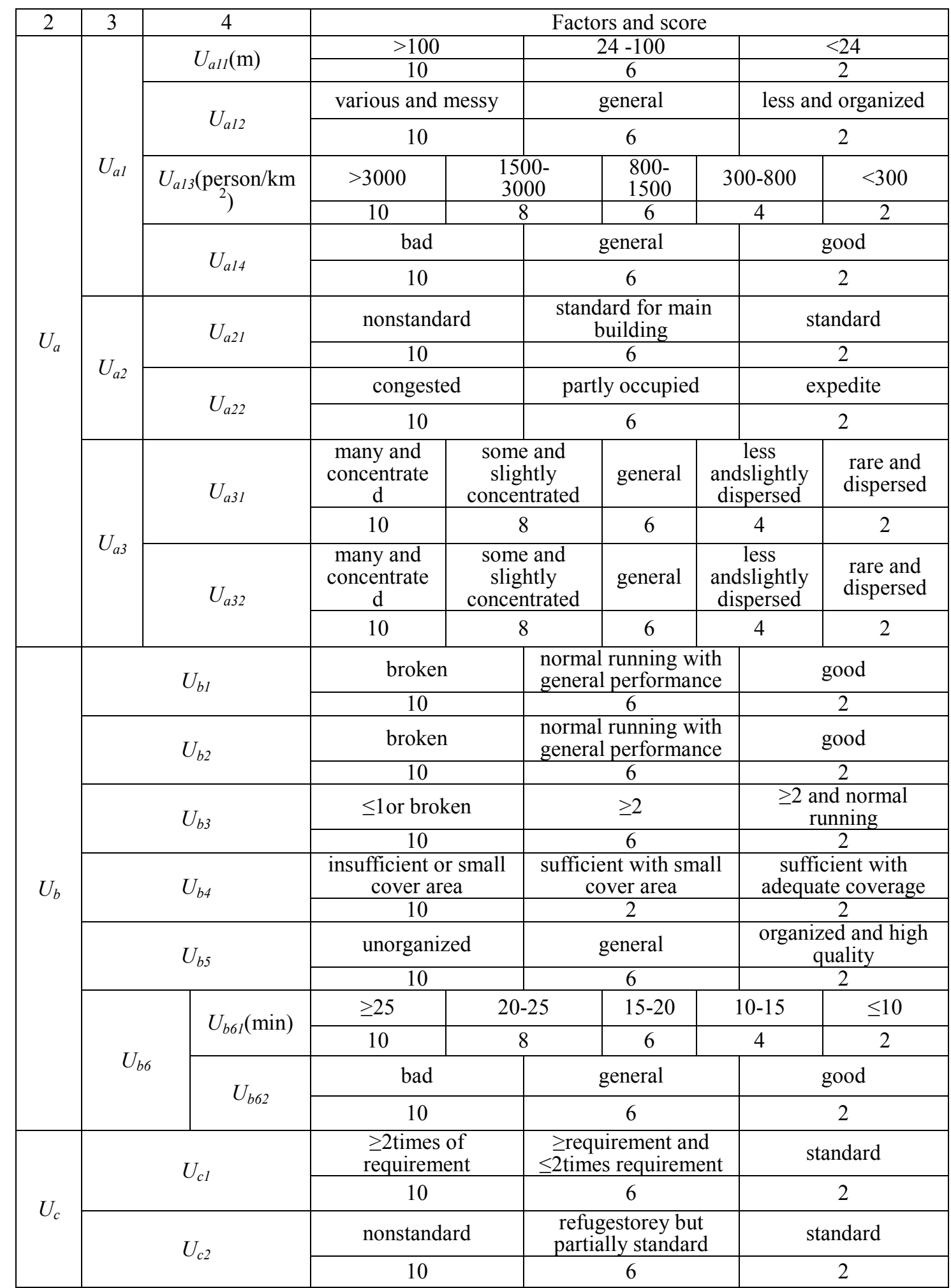


Table 3. (Continued)

\begin{tabular}{|c|c|c|c|c|c|}
\hline 2 & 3 & 4 & & Factors and score & \\
\hline \multirow{8}{*}{$U_{c}$} & \multirow{2}{*}{\multicolumn{2}{|c|}{$U_{c 3}$}} & $\begin{array}{c}\text { poor performance or } \\
\text { broken }\end{array}$ & $\begin{array}{c}\text { normal running with } \\
\text { general quality }\end{array}$ & good \\
\hline & & & 10 & 6 & 2 \\
\hline & \multirow{2}{*}{\multicolumn{2}{|c|}{$U_{c 4}$}} & $\begin{array}{l}\text { poor performance or } \\
\text { broken }\end{array}$ & $\begin{array}{l}\text { normal running with } \\
\text { general quality }\end{array}$ & good \\
\hline & & & 10 & 6 & 2 \\
\hline & \multirow{2}{*}{\multicolumn{2}{|c|}{$U_{c 5}(\mathrm{~m})$}} & $>50$ & $20-50$ & $<20$ \\
\hline & & & 10 & 6 & 2 \\
\hline & \multirow{2}{*}{\multicolumn{2}{|c|}{$U_{c 6}$}} & congested & partly occupied & expedite \\
\hline & & & 10 & 6 & 2 \\
\hline \multirow{6}{*}{$U_{d}$} & \multirow{2}{*}{\multicolumn{2}{|c|}{$U_{d l}$}} & bad & general & good \\
\hline & & & 10 & 6 & 2 \\
\hline & \multirow{2}{*}{\multicolumn{2}{|c|}{$U_{d 2}$}} & $\begin{array}{c}\text { unscheduled or } \\
\text { overlooked }\end{array}$ & $\begin{array}{c}\text { scheduled with poor } \\
\text { performance }\end{array}$ & $\begin{array}{c}\text { scheduled with good } \\
\text { performance }\end{array}$ \\
\hline & & & 10 & 6 & 2 \\
\hline & \multirow{2}{*}{\multicolumn{2}{|c|}{$U_{d 3}$}} & $\begin{array}{c}\text { unscheduled or } \\
\text { overlooked }\end{array}$ & $\begin{array}{c}\text { scheduled with poor } \\
\text { performance }\end{array}$ & $\begin{array}{c}\text { scheduled with good } \\
\text { performance }\end{array}$ \\
\hline & & & 10 & 6 & 2 \\
\hline \multirow{2}{*}{$U_{e}$} & \multirow{2}{*}{\multicolumn{2}{|c|}{ arson, firecracker }} & bad & general & good \\
\hline & & & 10 & 6 & 2 \\
\hline
\end{tabular}

Table 4. Score of each factor.

\begin{tabular}{|c|c|c|c|}
\hline Factors & Score & Factors & Score \\
\hline Height of the buildings $U_{a l l}$ & 6 & Finishing material $U_{a 12}$ & 6 \\
\hline Population density $U_{a 13}$ & 10 & Electrical aging $U_{a l 4}$ & 6 \\
\hline $\begin{array}{l}\text { The spacing between } \\
\text { adjacent buildings } U_{a 21}\end{array}$ & 6 & Fire passage $U_{a 22}$ & 6 \\
\hline Market $U_{a 31}$ & 6 & Ballroom, KTV, restaurant $U_{a 32}$ & 6 \\
\hline $\begin{array}{l}\text { Fire detecting and automatic } \\
\text { alarm system } U_{b l}\end{array}$ & 2 & Fire extinguishing system $U_{b 2}$ & 2 \\
\hline Fire elevator $U_{b 3}$ & 2 & Fire hydrant $U_{b 4}$ & 2 \\
\hline Part time fire brigade $U_{b 5}$ & 10 & The arriving time of fire brigade $U_{b 61}$ & 6 \\
\hline $\begin{array}{l}\text { The facility of the fire } \\
\text { brigade } U_{b 62}\end{array}$ & 6 & Fire compartment and smoke bay $U_{c l}$ & 6 \\
\hline Refuge storey $U_{c 2}$ & 2 & Smoke control system $U_{c 3}$ & 2 \\
\hline $\begin{array}{l}\text { Fire alarm address system } \\
U_{c 4}\end{array}$ & 2 & Evacuation distance $U_{c 5}$ & 6 \\
\hline $\begin{array}{l}\text { Evacuation exit and } \\
\text { emergency exit } U_{c 6}\end{array}$ & 6 & Fire-control publicity $U_{d l}$ & 6 \\
\hline $\begin{array}{l}\text { Fire patrol } U_{d 2} \\
\text { Arson, firecracker } U_{e}\end{array}$ & $\begin{array}{l}6 \\
2\end{array}$ & Facility maintenance $U_{d 3}$ & 6 \\
\hline
\end{tabular}




\section{Acknowledgment}

This research is supported by This research is supported by National Science Foundation for Distinguished Young Scholars of China (No. 11202004), National science and technology program of China (No. 2015BAK12B00), Project of BJAST (No. PXM2014-178215-000007). The authors deeply appreciate the support.

\section{References}

H.T. Chen, L.L. Lou, J.Z.Qiu, Accident cause analysis and evacuation countermeasures on the high rise building fires,International symposium on safety science andengineering in China (Procedia Engineering), 43 (2012) 23-27.

X.Y. Liu, H. Zhang, Q.M. Zhu, Factor analysis of high-rise building fires reasons and fire protection measures, International symposium on safety science and technology (Procedia Engineering), 45 (2012) 643-648.

X.Q. Sun, M.C. Luo, Fire risk assessment for super high-rise buildings, Procedia Engineering, 71 (2014) 492-501.
A.Cowlard, A. Bittern, C.Abecassis-Empis, J. Torero, Fire safety design for tall buildings, Procedia Engineering, 62 (2013) 169-181.

Q.K. Wang, S. Pan, On influence factors of Wuhan housing industry based on the AHP, Systems Engineering Procedia, 3 (2012) 158-165.

S.Y. Ren, Assessment on logistics warehouse fire risk based on analytic hierarchy process,International symposium on safety science and technology (Procedia Engineering), 45 (2012) 59-63.

Y. Zhang, Analysis on comprehensive risk assessment for urban fire: the case of Haikou city,Procedia Engineering, 52 (2013) 618-623.

J.P. Gao, Z.S. Xu, D.L. Liu, H.H. Cao, Application of the model based on fuzzy consistent matrix and AHP in the assessment of fire risk of subway tunnel,Procedia Engineering, 71 (2014) 591-596.

M. Omidvari, N. Mansouri, J. Nouri, A pattern of fire risk assessment and emergency management in educational center laboratories,Safety Science, 73 (2015) 34-42. 